

\title{
Malnutrition Survey among Children Aged One to Five Years in an Out-Patient Setting
} Oluwafemi $\mathrm{RO}^{1 *}$, Alonge $\mathrm{AO}^{2}$, Abiodun $\mathrm{MT}^{3}$

1Department of Paediatrics, Mother and Child Hospital, Akure, Nigeria

2Department of Paediatrics, Federal Medical Centre, Owo, Nigeria

${ }^{3}$ Department of Child Health, University of Benin Teaching Hospital, Benin City, Nigeria

*Correspondence: Dr RO Oluwafemi, Department of Paediatrics, Mother and Child Hospital, Akure, Nigeria. E-mail: bankyfem@yahoo.com; ORCID - https://orcid.org/0000-0001-5122-6577.

\begin{abstract}
Background: Malnutrition, though rarely listed as the direct cause, is estimated to contribute to more than half of all childhood deaths in the developing countries. The vicious cycle of poverty, recurrent infections and ignorance remain the major predisposing factors to this disease.

Objectives: To determine the prevalence of malnutrition among children aged one to five years attending the OutPatient Department (OPD) of a Nigerian Specialist Hospital, to describe the major associated co-morbidities and associated socio-cultural factors.

Methods: All the children aged 1 to 5 years attending the OPD of Mother and Child Hospital, Akure, Nigeria were recruited into the study from September 2018 to November 2018. In addition to basic bio-data, sociodemographic data, and clinical diagnoses, the Z-scores of the anthropometric parameters were calculated using the WHO AnthroPlus software.

Results: A total of 577 children were studied with a male preponderance of $58.1 \%$. The prevalence of underweight, stunting and wasting were $18.5 \%, 15.9 \%$ and $20.8 \%$ respectively. Malaria was the leading co-morbidity both in its complicated and uncomplicated forms. The identified associated socio-cultural factors included low socioeconomic status, large family size and some paternal social habits.

Conclusion: The prevalence rate of malnutrition among the children was high despite the high literacy and socioeconomic status of the parents.
\end{abstract}

Keywords: Childhood, Malnutrition, Stunting, Underweight, Wasting, Nigeria.

\section{Introduction}

Malnutrition occurs in children as a result of either recent or past inadequate food intake. [1] The World Health Organization (WHO) defines malnutrition as an imbalance between nutrient and energy supply, and the body's demand for them to ensure growth, maintenance and specific functions. ${ }^{[2]}$ Malnutrition is a major public health problem affecting more than 900 million individuals, ${ }^{[3,4]}$ and accounting either directly or indirectly, for about $54 \%$ of childhood deaths worldwide. [2, 3] In the year 2019, globally, 144 million children under the age of five years were 
stunted, 47 million were wasted and 38 million overweight. [5] The global prevalence of stunting, underweight and wasting was $21.3 \%, 13.3 \%$ and $7.3 \%$ respectively. ${ }^{[5]}$ The prevalence rates were higher in Nigeria with $43.6 \%, 31.5 \%$ and $10.8 \%$ respectively. [2, 3, 5] This portends grave consequences for the future of Nigerian children.

Substantial efforts made to reduce under-five mortality rates in the last two decades, as initiated by the defunct Millennium Development Goals (MDG's) project of the United Nations, led to a drop in the under-five mortality rate of about $53 \%$ from 9 per 1000 (1990) to 4.3 per 1000 deaths (2015), but with minimal effect on stemming malnutrition. ${ }^{[2]}$ Survivors with chronic under-nutrition often develop growth failure, poor intellectual and physical development, increased susceptibility to infections and higher incidences of other chronic diseases such as truncal obesity, cardiovascular diseases and Type 2 Diabetes mellitus. ${ }^{[5,6]}$ Such children grow up to become adults with poor intellectual performance and therefore, of low productivity. Furthermore, the girl-child who suffers chronic malnutrition may become a stunted adult with poor development of the pelvic bones resulting in cephalo-pelvic disproportion during childbirth and increased risk of a difficult delivery. This also poses more dangers to their future offspring. The cumulative effects of these include low productivity and increased burden of children with neurological deficits, not only to an already over-stretched health system but also to the entire economy of the nation.

Despite enhanced economic development worldwide in the last two decades, there has been minimal impact on stemming the tide of the malnutrition scourge. Children less than five years are mostly affected. [4 - 6] Therefore, this vulnerable age group must constitute a focus for early identification and treatment to reduce the burden of the disease. While there is no racial or sexual predilection to the development of the disease, a strong link of poverty with malnutrition has been established, particularly in developing countries. $[1,6]$

The nutritional status of children is assessed using growth parameters. Under-nutrition, a form of malnutrition can be classified into three; stunting, wasting and underweight. Stunting (height for age less than-2 Standard deviation (SD) of the WHO Child Growth Standards mean) reflects the cumulative effects of prolonged undernutrition and infections which may predate birth; it is an indication of a long-term restriction of a child's growth potential.[6 - 8] Wasting (weight for height less than -2 SD of the WHO Child Growth Standards mean), in children is a symptom of acute undernutrition, usually as a consequence of insufficient food intake or a high incidence of infectious diseases, especially diarrhoea. $[6,9,10]$ Underweight (weight for age less than -2 SD of the WHO Child Growth Standards mean) is an indicator of acute malnutrition. [8] The mid-arm circumference (MAC) can also be used for the assessment of nutritional status, the major determinants being the bulk of arm muscle and subcutaneous fat. [7] MAC is less affected than weight and heightbased indices. ${ }^{[7]}$ Most children presenting to the hospital with undernutrition usually have accompanying ailments.

Therefore, the objectives of the study included the determination of the prevalence of malnutrition among children aged one to five years attending the Out-Patient Department (OPD) of a Nigerian Specialist Hospital and the description of the major associated comorbidities and predisposing socio-cultural factors.

\section{Methods}

\section{Study location}


The study was carried out at the Mother and Child Hospital, Akure (MCHA), Nigeria. It is a very busy, purpose-built 100-bed (60 obstetrics and 40 paediatric beds), public health facility providing specialized free health services to the populace in the state capital and surrounding communities. Akure is the capital of Ondo State, in the south-west geo-political zone of Nigeria with a land expanse of 991 square kilometres. [11]

\section{Ethical considerations}

Ethical clearance was obtained from the Research and Ethics committee of the MCHA, while informed consent was obtained from parents of all the children recruited into the study.

\section{Study design}

This was a cross-sectional and hospital-based study.

Inclusion criteria

Children aged one to five years presenting at the Children Emergency Unit and the Out-patient Department (OPD) of the MCHA from September 2018 to November 2018.

Exclusion criteria

All children with underlying chronic illnesses such as tuberculosis and congenital abnormalities were excluded from the study.

\section{Data Collection}

All subjects were duly evaluated to determine the clinical diagnosis and other co-morbidities. The critically-ill were hospitalized while the others were treated on an out-patient basis. The sex, age, ethnicity, address, parents' bio-data, social history and habits were documented in a research proforma. The anthropometric parameters i.e weight, height, occipitofrontal circumference (OFC), and mid-arm circumference (MAC) of each child were also recorded.

\section{Anthropometric measurements \\ Bodyweight}

Each child was weighed using the RGZ-20 weighing scale which was calibrated in grams to the nearest 25g. It was adjusted for zero error before each reading. Other measures taken to ensure the reliability of results included weekly standardization of the weighing scale, using known weights.

\section{Length/ height}

The length was measured in centimetres to one decimal place for children less than two years using a metal anthropometric linear rule fixed to a horizontal flat board. The board had a fixed head plate at the zero end of the metal rule and a sliding footplate. An assistant held the baby in position, making sure that the head was flushed with the fixed headboard, the eye-sockets were in the same vertical plane as the external auditory meati, the back was flat on the board and the knees were straight. The investigator then slid the footplate to gently touch the sole of the child's foot and read off the length. ${ }^{[12]}$ The stadiometer (RGZ-20) was used for the children above two years of age.

\section{Weight-for-age}

The Modified Wellcome Classification [10,13] was also used to screen the children because it is one of the methods used for clinical diagnosis of malnutrition by clinicians. It classifies malnutrition into kwashiorkor, underweight kwashiorkor, underweight, marasmus and marasmic kwashiorkor based on the percentage of expected weight-for-age and the presence or absence of oedema. Between 60 and $80 \%$ of expected weight defined underweight in the absence of oedema or underweight-kwashiorkor when oedema was present, greater than $80 \%$ with oedema was kwashiorkor, under $60 \%$ of the expected weight was marasmus in the absence of oedema, and marasmic-kwashiorkor when oedema was present. [7, 13]

Age and sex standardized Body Mass Index Zscores (BAZ) were defined using the World Health Organization (WHO) $[7,8,14]$ Growth Standards BMI-for-age Z-score cut-points of $<-2.0,>1.0,>2.0$ and $>3.0$ defining wasting, 
risk of overweight, overweight and obesity, respectively. Normal anthropometric Z-score was defined as $-1.0 \mathrm{SD}$ to $+1.0 \mathrm{SD}$. [15] Height-forAge Z-score (HAZ) cut-points of < -2.0 indicates stunting and $-1.0 \mathrm{SD}$ to $+1.0 \mathrm{SD}$ was taken as normal height-for-age, while $>+1.0$ indicated that the raw data was +1 SD above the reference point. Weight-for-Age Z-score (WAZ) cut point of $<-2.0$ defined low weight-for-age (underweight) and raw data $>+1.0$ indicated normal weight-for-age. WAZ, however, reflected body mass relative to chronologic age and it may be influenced by both height-for-age and weightfor-height. ${ }^{[7]}$

\section{Mid Arm Circumference (MAC)}

The MAC was measured to the nearest $0.1 \mathrm{~cm}$ with a non-stretchable tape at the mid-point between the tip of the shoulder and the tip of the elbow (olecranon process and the acromion). ${ }^{[7,16]}$ MAC $\quad<11.5 \mathrm{~cm}$ indicated severe acute malnutrition and risk of death. MAC between $11.5 \mathrm{~cm}-13.5 \mathrm{~cm}$ indicated mild to moderate malnutrition needing counselling, supplementation and growth monitoring while MAC $>13.5 \mathrm{~cm}$ indicated good nutritional status.

\section{Family size}

Family size was defined as the number of people in the family. A family was described as small if it comprised six or less, including the father and the mother. On the other hand, a large family comprised the father, the mother and more than four children. [17]

\section{Socio-economic status}

The socio-economic status of each family was determined using the model described by Ogunlesi et al. [18] taking into account maternal income, education and occupation as well as paternal income, education and occupation. There were five socio-economic classes (I to V) which were ranked in descending order with class I being the highest and class V, the lowest. For the current study, the classes were grouped as an upper socioeconomic class (SEC) (classes I and II) middle SEC (class III) and lower SEC (classes IV and V).

\section{Data Analysis}

The data were analysed using the Statistical Package for Social Science (SPSS) version 20.0 (Windows Inc; Chicago, IL, USA). The anthropometric Z-scores were calculated using the WHO AnthroPlus software [15] derived using the WHO Child Growth Standards. Normal anthropometric Z-score was defined as $-1.0 \mathrm{SD}$ to +1.0. SD. [15] Comparison of the sociodemographic parameters of malnourished and normal participants (using BAZ) was subjected to Carls Pearson's Chi-Square test. Statistically significant difference was defined by $p$ values $<0.05$.

\section{Results}

General and socio-demographic characteristics A total of 1,050 children attended the OPD during the period of study. Of this number, 577 (55\%) patients were aged 1 to 5 years. Three hundred and forty-seven $(60.1 \%)$ were aged between 1 and 2 years while $230(39.9 \%)$ were above 2 years of age. The mean age $( \pm S D)$ at presentation was $2.6 \pm 2.1$ years. In all, $58.1 \%$ were males with a male-to-female ratio of 1.4: 1 .

All the parents were married. Table I shows the socio-demographic characteristics of the children. Over half $(53.2 \%)$ of them belonged to the upper socio-economic class, $17 \%$ were in the middle class while $29.8 \%$ were in the lower socioeconomic class.

The majority of the children were of the Yoruba extraction $(90.1 \%)$. The mean family size was $5.2 \pm 1.2$ with $69 \%$ of the children belonging to small-sized families while 176 (30.5\%) belonged to large-sized families. Further, 272 (47.1\%) of the mothers had tertiary level education, while 217 $(37.6 \%)$ and $83(14.4 \%)$ had secondary and 
primary education respectively; only $5(0.9 \%)$ were not formally educated. Majority of the fathers $(89.8 \%)$ fathers neither smoked nor drank alcohol.

Using the modified Wellcome classification of malnutrition, $78(13.5 \%)$ of the children had marasmus, 99 (17.2\%) had underweight, while $400(69.3 \%)$ were normal (Table II). The MAC of $81(14.0 \%)$ children were less than $11.5 \mathrm{~cm}$ (severe acute malnutrition), 79 (13.7\%) had mild to moderate malnutrition while 417 (72.3\%) were well-nourished.

The distribution of the children according to the Z-scores of the anthropometric parameters is shown in Table III. Analysis of the BAZ revealed that $120(20.8 \%)$ of the children had BAZ of <-2 SD and $410(71.1 \%)$ subjects had normal BAZ. Ninety-two (15.9\%) were stunted while 376 (65.2\%) had normal height/length. On the other hand, $107(18.5 \%)$ had underweight while 430 $(74.5 \%)$ had normal weight-for-age. The mean $( \pm \mathrm{SD})$ values of the BMI, height/length and weight are also presented as a footnote to Table III.

Table IV shows the comparison of the sociodemographic parameters of malnourished and well-nourished children (using BAZ). There were more malnourished children in the age group 1 to 2 years compared to the other age groups but the difference was not statistically significant. There were significantly more malnourished children among the lower $(75.9 \%)$ and middle socioeconomic classes $(90.0 \%)$ compared to the upper socio-economic class $(47.2 \%)$. There was also a significantly higher frequency of malnutrition among the children from large-sized families and among those whose fathers indulged in alcoholism or cigarette smoking.
Table V shows the various co-morbidities in the children at the time of presentation. Malaria was the leading co-morbidity (37.6\%) both in its complicated and uncomplicated forms. This was followed by Upper Respiratory Tract Infections $(15.8 \%)$ and gastroenteritis (13.3\%). Sepsis and pneumonia were less frequent co-morbidities.

\section{Discussion}

Wasting was the most frequent $(20.8 \%)$ form of malnutrition in the present study. This value is higher than the prevalence rate reported from Lagos (10\%) ${ }^{[19]}$ and Ondo State in general (6.6\%). [20] It is also higher than the prevalence rate reported from the South-eastern part of Nigeria (11.9\%), south-south $(11.1 \%)$, southwest $(10 \%)$, northeast (19.5\%), and northcentral (11.7\%) parts of Nigeria. ${ }^{[20]}$ This observation may be attributed to the fact that the children in the present study were ill children recruited from a health facility whereas the children in the national survey were randomly selected from the general population of apparently healthy Nigerian children. Acute illnesses associated with fever (leading to increased metabolism) coupled with the loss of appetite will culminate in acute malnutrition.

The study location is a referral centre and the facility is accessed by mixed groups of people from the township, the neighbouring villages and adjacent States. Though the population is a relatively literate and predominantly high socioeconomic class, yet the recorded prevalence rate of malnutrition is high hence, the magnitude of the problem must be met with a response that reflects the scale and gravity of the situation. The study revealed that $18.5 \%$ of the children were underweight while the prevalence rate of stunting was $15.9 \%$. 
Table I: Socio-demographic characteristics of the study participants

\begin{tabular}{|c|c|c|}
\hline & Frequency & Percentage \\
\hline \multicolumn{3}{|l|}{ Age (Years) } \\
\hline $1-2$ & 347 & 60.1 \\
\hline$>2-5$ & 230 & 39.9 \\
\hline \multicolumn{3}{|l|}{ Sex } \\
\hline Male & 335 & 58.1 \\
\hline Female & 242 & 41.9 \\
\hline \multicolumn{3}{|l|}{ Socio-economic classes } \\
\hline Lower & 172 & 29.8 \\
\hline Middle & 98 & 17.0 \\
\hline Upper & 307 & 53.2 \\
\hline \multicolumn{3}{|l|}{ Family size } \\
\hline$\leq 6$ people & 401 & 69.5 \\
\hline$>6$ people & 176 & 30.5 \\
\hline Mothers' level of education & 83 & 14.4 \\
\hline \multicolumn{3}{|l|}{ Primary } \\
\hline Secondary & 217 & 37.6 \\
\hline Tertiary & 272 & 47.1 \\
\hline None & 5 & 0.9 \\
\hline \multicolumn{3}{|l|}{ Ethnic groups } \\
\hline Yoruba & 520 & 90.1 \\
\hline Igbo & 20 & 3.5 \\
\hline Edo & 4 & 0.7 \\
\hline Others & 33 & 5.7 \\
\hline Paternal social habits & 518 & 89.8 \\
\hline \multicolumn{3}{|l|}{ No alcoholism or tobacco smoking } \\
\hline Alcoholism only & 52 & 9.0 \\
\hline Alcoholism and tobacco smoking & 7 & 1.2 \\
\hline
\end{tabular}

Table II: Weight-for-Age (modified Wellcome) classification and mid-arm circumference of the subjects

\begin{tabular}{lll}
\hline Weight as a percentage of normal & Frequency & Percentage \\
\hline$<60$ & 78 & 13.5 \\
$60-80$ & 99 & 17.2 \\
$>80$ & 400 & 69.3 \\
Total & 577 & $\mathbf{1 0 0 . 0}$ \\
MAC (cm) & & \\
$<11.5$ & 81 & 14.0 \\
$11.5-13.5$ & 79 & 13.7 \\
$>13.5$ & 417 & 72.3 \\
Total & 577 & $\mathbf{1 0 0 . 0}$ \\
\hline
\end{tabular}

MAC - Mid Arm circumference; None had oedematous malnutrition. 
Table III: Distribution of the study participants by the Z-Scores of their anthropometric parameters

\begin{tabular}{lll}
\hline Anthropometric Z-scores & Frequency & Percentage \\
\hline BAZ & 120 & \\
$<-2.0$ & 410 & 20.8 \\
$<-1.0$ to $>+1.0$ & 39 & 71.1 \\
$>+2.0$ & 8 & 6.8 \\
$>+3.0$ & & 1.4 \\
HAZ & 92 & \\
$<-2.0$ & 376 & 15.9 \\
$<-1.0$ to $>+1.0$ & 98 & 65.2 \\
$>+2.0$ & 11 & 17.0 \\
$>+3.0$ & & 1.9 \\
WAZ & 107 & \\
$<-2.0$ & 430 & 18.5 \\
$<-1.0$ to $>+1.0$ & 38 & 74.5 \\
$>+2.0$ & 2 & 6.6 \\
$>+3.0$ & 2 & 0.4 \\
\hline Mean BMI: $16.7 \pm 7.6$ kg/m ${ }^{2}$ Mean length/height: $86.6 \pm 14.0$ cm; Mean body weight: $12.5 \pm 8.8$ kg \\
BAZ: Body Mass Index-for-Age Z-score; HAZ: Height-for-Age Z-score; WAZ: Weight-for-Age Z-score.
\end{tabular}

The prevalence rate of underweight reported by Akeredolu, et al. ${ }^{[19]}$ in Lagos (13\%) was lower whereas the prevalence rate of stunting was higher $(16.3 \%)$ compared to the findings in the present study. Similar to earlier reports from Enugu [13] and Ghana, [2] there was no significant difference concerning gender in the current study. All the parents in this study were married; therefore, the issue of unwanted pregnancy was not a confounder. Forty-seven per cent of the mothers had tertiary level education while only $0.9 \%$ of them never went to school, therefore, expectedly, ignorance should be minimal in this population. Yet, the prevalence rates of malnutrition were high. This implies that the community probably needs to imbibe better child-care practices to reverse this trend.

Wasting represents a more accurate reflection of the effects of current or recent illnesses and shortterm food shortage, resulting in weight loss. It also indicates tissue and body fat deficit when the bodyweight is compared to the expected value for height. [15, 19, 21] Infections, particularly frequent or persistent diarrhoea, pneumonia, sepsis and malaria tend to undermine a child's nutritional status. ${ }^{[2]}$ In the current study, malaria was the most prevalent co-morbidity both in its complicated and uncomplicated forms. This is similar to the finding in an earlier study conducted in the same centre [22] and Benin. [23] Malaria was closely followed by Upper Respiratory Tract Infections (URTI) and gastroenteritis. Sepsis and pneumonia were less common co-morbidities in the current study; similar to earlier reports from Enugu [13] while only diarrhoea was the major co-morbidity in the Ghanaian study. [2] The socio-cultural factors associated with malnutrition in the current study included low socioeconomic status, large family size and use of alcohol and cigarette smoking by fathers. The reason for this may be that poor and large families, already with low purchasing power for adequate nutritious foods for their families also deduct money for these social habits. 
Table IV: Comparison of the socio-demographic parameters of malnourished and normal participants (using BAZ)

\begin{tabular}{|c|c|c|c|c|c|}
\hline & Malnourished & Normal & $\chi^{2}$ & $d f$ & p-value \\
\hline \multicolumn{6}{|l|}{ Age (Years) } \\
\hline $1-2$ & $217(59.3)$ & $130(61.6)$ & 0.301 & 1 & $0.597^{*}$ \\
\hline$>2-5$ & $149(40.7)$ & $81(38.4)$ & & & \\
\hline \multicolumn{6}{|l|}{ Sex } \\
\hline Male & $223(60.9)$ & $112(53.1)$ & 3.386 & 1 & 0.066 \\
\hline Female & $143(39.1)$ & 99 (46.9) & & & \\
\hline \multicolumn{6}{|l|}{ Family size } \\
\hline$\leq 6$ & $251(68.6)$ & $150(71.1)$ & 0.423 & 1 & 0.022 \\
\hline$>6$ & $115(31.4)$ & $61(28.9)$ & & & \\
\hline \multicolumn{6}{|l|}{ Socio-economic Classes } \\
\hline Lower & $123(33.6)$ & $39(18.5)$ & 96.074 & 2 & 0.000 \\
\hline Middle & $98(26.8)$ & $10(4.7)$ & & & \\
\hline Upper & $145(39.6)$ & $162(76.8)$ & & & \\
\hline \multicolumn{6}{|l|}{ Paternal social habits } \\
\hline No alcoholism or tobacco smoking & $317(86.7)$ & $201(95.3)$ & 6.364 & 2 & 0.001 \\
\hline Alcoholism only & $43(11.7)$ & $9(4.3)$ & & & \\
\hline Alcoholism and tobacco smoking & $6(1.6)$ & $1(0.4)$ & & & \\
\hline
\end{tabular}

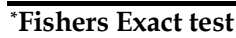

Figures in parentheses are percentages of the total in columns

The significant association between lower socioeconomic status and malnutrition, as observed in the current study is comparable to the findings in Enugu [13] and Ghana. [2] Family size of greater than six was associated with malnutrition in the current study, similar to earlier findings from Ile-Ife, southwest, Nigeria where the total number of people in a family is reportedly related to the incidence of adverse circumstances. [24] The study further showed that the food available to larger families ( $>4$ children) per head was frequently lower than that available to smaller families and this difference reflected in the growth rate of the children. [24] Other researchers from Ethiopia also reported similar findings that children living in households with greater than or equal to five family members were 2.72 times more likely to be malnourished than those children living in households with smaller family size. [25]
The prevalence rate of stunting in the current study was $15.9 \%$. Stunting reflects a process of failure to reach linear growth potential as a result of suboptimal health and/or nutritional conditions. ${ }^{[7]}$ On a population basis, stunting can also be explained from the point of view of chronic food deprivation either from inadequate intake, poor quality food, poverty, ignorance and continued co-morbidities with associated loss of appetite. [7] Stunting is a common occurrence in the developing world, Nigeria inclusive, due to the aforementioned factors. [11] However, the prevalence rate of stunting in the current study is lower than rates reported from Ilorin (23.6\%), [26] Lagos (16.3\%) [19] and Jos (18\%) [27] all within Nigeria but higher than in Tanzania (13\%). [28] These children with stunting are usually prone to poor brain development and subsequently low intelligent quotient. [21] Another grave 
consequence of stunting is premature death in this set of children; unfortunately, more than $90 \%$ of the world's stunted children reside in Africa. [21]

Table V: Pattern of co-morbidities among the study participants

\begin{tabular}{lll}
\hline Co-morbidities & Frequency & Percentage \\
\hline Uncomplicated malaria & 132 & 22.8 \\
Severe malaria & 95 & 16.5 \\
URTI & 91 & 15.8 \\
Gastroenteritis & 77 & 13.3 \\
Sepsis & 52 & 9.1 \\
Pneumonia & 38 & 6.6 \\
Acute severe asthma & 21 & 3.6 \\
Bronchiolitis & 17 & 2.9 \\
Meningitis & 12 & 2.1 \\
Sickle Cell Anaemia & 8 & 1.4 \\
Others & 34 & 5.9 \\
Total & 577 & $\mathbf{1 0 0 . 0}$ \\
\hline
\end{tabular}

Others - Accidental poisoning, Febrile convulsion, and Congenital Heart Diseases.

URTI - Upper Respiratory Tract Infections.

On the other hand, the prevalence rate of underweight in the current study was $18.5 \%$. It is lower than the national figure of $31.5 \%$, [20] but higher than the rate reported from Lagos (13\%). [19] Malnutrition generally is the underlying cause of morbidity and mortality in a large proportion of under-five children in Nigeria. It contributes to more than 50 per cent of deaths of children in this age group. [1, 11] It also causes direct structural damage to the brain, impairing motor development and exploratory behaviour. [11, 21] The Wellcome classification and the use of MAC in the current study revealed that $13.5 \%$ and $14.0 \%$ respectively of the children had one form of malnutrition or the other. This rate is higher than the 3.1\% reported from Ilorin, [29] northcentral Nigeria. This situation calls for a new approach to improving the health of the Nigerian child. Policies, legislation and funding are needed to improve health care delivery. Policies and strategies which highlight adequate infant and child feeding, complementary feeding, de-worming (to improve the nutritional status), immunization against the childhood killer diseases, hand-washing, water and food sanitation (to reduce morbidity and mortality), use of the insecticide-treated mosquito nets to prevent malaria and of course the improved health of the mothers which in turn affect the health of the children, need to be popularized.

\section{Conclusion}

The prevalence rate of malnutrition among under-five children in the current study was high, though the parents were literate and the majority belonged to the upper socio-economic class. Malaria was the leading co-morbidity both in its complicated and uncomplicated forms. Malnutrition is more likely to occur in children with acute illness and this, therefore, suggests that routine nutritional assessment of ill children should be done for early identification and institution of proper steps to ameliorate the clinical conditions of the affected children for subsequent nutritional rehabilitation.

Authors' Contributions: ORO and AAO conceived and designed the study and collected the data. AMT analysed the data. All the authors participated in 
drafting the manuscript. All the authors approved the final version of the manuscript.

Conflicts of interest: None declared.

Funding: Self-funded.

Publication History: Submitted 27 April 2020; Accepted 07 October 2020.

\section{References}

1. Ulasi TO, Ebenebe J. Nutritional disorders in childhood. In: Azubuike JC, Nkaginieme KEO (Editors). Paediatrics and Child Health in a Tropical Region. 2nd Edition. African Educational Services, Owerri, Nigeria. 2007. p. 250-267.

2. Tette EMA, Sifah EK and Nartey ET. Factors affecting malnutrition in children and the uptake of interventions to prevent the condition. BMC Pediatr 2015; 15: 189. doi:10.1186/s12887-015-0496-3.

3. Vinicius JBM, Telma MM, Toledo F, Luciane P, Grillo E, Maria Do Carmo PF, et.al Longlasting effects of Under-nutrition. Int J Environ Res Public Health 2011; 8: 1817-1846. doi:10.3390/ijerph8061817.

4. Grantham-McGregor S, Cheung YB, Cueto S, Glewwe P, Richter L, Strupp B. Developmental potential in the first 5 years for children in developing countries. Lancet. 2007; 369: 60-70. doi:10.1016/S01406736(07)60032-4.

5. World Health Organization. Nutrition Landscape Information System (NLIS). Country Profile Indicators 2010: 1. https:/ /apps.who.int/iris/handle/10665/ 44397 Accessed on 25 April 2020.

6. Mary EP. Protein Energy Malnutrition, Pathophysiology, clinical consequences and treatment. In: Walker AW, Christopher D, Watkin JB (Editors). Nutrition in Paediatrics. London. Blackwell Waterson. 2008. p. 171184.
7. Ulasi TO, Ebenebe J. Nutritional disorders in childhood. In: Azubuike JC, Nkaginieme KEO (Editors). Paediatrics and Child Health in a Tropical Region. 3rd Edition. African Educational Services, Lagos, Nigeria. 2016. p. 697-700.

8. Anderson LN, Carsley S, Lebovic G, Borkhoff CM, Maguire JL, Parkin PC, et al. Misclassification of child body mass index from cut-points defined by rounded percentiles instead of Z-scores. BMC Res Notes 2017; 10: 639. https:/ / doi.org/10.1186/s13104-017-2983-0.

9. Caulfield LE, de Onis M, Blossner M, Black RE. Undernutrition as an underlying cause of child deaths associated with diarrhoea, pneumonia, malaria, and measles. Am J Clin Nutr 2004; 80: 193-198. doi:10.1093/ajen/80.1.193.

10. Gernaat HB, Voorhoeve WH. A new classification of Acute Protein Energy Malnutrition. J Trop Pediatr 2000; 46: 97106. https://doi.org/10.1093/tropej/46.2.97.

11. National Population Commission (NPC) [Nigeria] and ICF International. 2014. Nigeria Demographic and Health Survey 2013. Abuja, Nigeria, and Rockville, Maryland, USA: NPC and ICF International. Nutrition of Children and women 2014:175-176. Available from: www.dhsprogram.com /pubs/pdf/fr293/fr293.pdf Accessed 12 September 2020.

12. Lawrence EJ. A matter of size: Evaluating the growth-restricted neonate; accurately measuring the neonate. Advanced neonatal care. Pediatrics 2006; 6: 313322. doi:10.1016/j.adnc.2006.08.006.

13. Ubesie AC, Ibeziako NS, Ndiokwelu CI, Uzoka CM, Nwafor CA. Under-five Protein Energy Malnutrition admitted at the University of Nigeria Teaching Hospital, Enugu: a 10-year retrospective review. Nutr J 2012; 11: 43. https://doi.org/10.1186/14752891-11-43 Accessed 20 August 2020. 
14. De Onis M, Lobstein T. Defining obesity risk status in the general childhood population: which cut-offs should we use? Int J Pediatr Obes 2010; 5: 458-460. doi:10.3109/17477161003615583.

15. Blössner M, Siyam A, Borghi E, Onyango A, Mercedes de Onis. WHO AnthroPlus for personal computers Manual: Software for assessing growth of the world's children and adolescents. Geneva: WHO, 2009. http://www.who.int/growthref/tools/en Accessed 13 July 2020.

16. Rovner AJ, Zemel B. Growth and Physical Maturation. In: Mulberg AE; Silber SA, van den Anker JN (Editors). Pediatric Drug Development: Concepts and Applications. John Wiley and Sons. 2009: p. 370.

17. Treas J. Post-war trends in family size. Demography 1981; 18: 321-334. http://www.jstor.org/stable/2061000.

18. Ogunlesi TA, Dedeke IOF, Kuponiyi OT. Socio-economic classification of children attending Specialist Paediatric Centres in Ogun State, Nigeria. Niger Med Pract 2008; 54: 21-25. doi:10.4314/nmp.v54i1.28943.

19. Akeredolu IA, Osisanya JO, SerikiMosadolorun JS, Okorafor U. Mothers' Nutritional Knowledge, Infant Feeding Practices and Nutritional Status of Children (0-24 months) in Lagos State, Nigeria. Eur J Nutr Food Safety 2014; 4: 364-374. https://doi.org/10.9734/EJNFS/2014/7604.

20. National Demographic and Health Survey (NDHS) 2018. http://www.neuroaro.com/sites/default/fi les/downloadables/ Accessed 11 February 2019.

21. WHO. Collaborative Study Team on the Role of Breastfeeding in the Prevention of Infant Mortality. Effects of Breastfeeding on Infant and Child Mortality due to Infectious Diseases in less Developed Countries: A pool of Analysis. Lancet 2000; 355: 451-455. https://doi.org/10.1016/SO140-

6736(00)82011-5.

22. Oluwafemi RO, Abiodun MT. Morbidity and mortality pattern in Emergency Paediatric Unit of Mother and Child Hospital, Akure, Nigeria. Ann Biomed Sci 2016;15: 151-159.

23. Abhulimhen-Iyoha BI, Okolo AA. Morbidity and mortality of childhood illnesses at the Emergency Paediatric Unit of the University of Benin Teaching Hospital, Benin City. Niger J Paediatr 2012; 39: 71-74. http://dx.doi.org/10.4314/njp.v39i2.7.

24. Ajao KO, Ojofeitimi EO, Adebayo AA, Fatusi AO, Afolabi OT. Influence of family size, household food security status, and child care practices on the nutritional status of Underfive children in Ile-Ife, Nigeria. Afr J Reprod Health 2010; 14: 117-128.

25. Gebre A, Reddy PS, Mulugeta A, Sedik Y, Molla S. Prevalence of malnutrition and associated factors among Under-Five children in Pastoral Communities of Afar Regional State, Northeast Ethiopia: A community-based cross-sectional study. J Nutr Metab 2019; 10: 1155. https://doi.org/10.1155/2019/918760 9

26. Babatunde RO, Olagunju FI, Fakayode SB, Sola-Ojo FE. Prevalence and determinants of malnutrition among Under-Five children of farming households in Kwara State, Nigeria. J Agric Sci. 2011; 3: 173-181. doi:10.5539/jas.v3n3p173.

27. Okeke IE, Thandi P. Malnutrition in acutely ill children at the Paediatric Emergency Unit in a tertiary hospital in Nigeria. Niger Med J 2015; 56: 113-117. doi:10.4103/03001652.150695 .

28. Safari JG, Kimambo SC, Welarimira JEL. Feeding practices and nutritional status of infants in Morogoro Municipality, Tanzania. 
Tanzan J Health Res 2013; 15: 178-185. doiI10.4314/thrb.v15i3.5.
29. Olagunju FI. Morbidity and mortality report in Ilorin. Annual Paediatr Digest 2006; 2: 7782.

(C) (5) 5 No
$\begin{array}{r}\text { This is an Open Access document licensed for distribution under the terms and conditions of the Creative } \\ \text { Commons Attribution License (http://creativecommons.org/licenses/by-nc/4.0). This permits } \\ \text { unrestricted, non-commercial use, reproduction and distribution in any medium provided the original } \\ \text { source is adequately cited and credited. }\end{array}$

